\title{
Bruk av nettbrett til digitale innleveringer i fag med matematisk notasjon
}

\author{
K.E.T. Giljarhus, O. Mikkelsen, Institutt for maskin, bygg og materialteknologi, Universitetet $i$ \\ Stavanger
}

SAMMENDRAG: MNT-fag har utstrakt bruk av matematisk notasjon og diagrammer. For øvingsoppgaver og eksamen i disse fagene blir det fortsatt overveiende brukt penn og papir. Samtidig er det et økende fokus på digitalisering. Digitale innleveringer og eksamen har flere fordeler; blant annet vil det minske administrativt arbeid med lagring og distribusjon av papirbesvarelser og det vil gjøre sensors arbeid enklere da sensur kan utføres digitalt og med økt lesbarhet. Å ha innleveringer på en heldigital form kan også ha en klar pedagogisk fordel. Med de matematiske uttrykkene i en digital form kan utrykkene utnyttes til løsning av likninger i beregningsprogrammer og studentene kan gis tilbakemeldinger underveis i løsningsprosessen.

A skrive inn matematiske uttrykk på en PC er ofte tungvint og krever bruk av spesialisert notasjon som LaTeX eller pek-og-klikk verktøy som Microsoft sin ligningseditor i Word. Det samme gjelder for eksamensoppgaver i for eksempel Inspera. Det finnes også andre løsninger for digitalisering i dag, hovedsakelig basert på scanning av besvarelser. Dette innfrir noen av fordelene til digitale innleveringer, men man mangler fortsatt lesbarheten til en heldigital form, og man har ikke mulighet til å gjøre en analyse av besvarelsen for å få de pedagogiske mulighetene.

Det har i de siste årene skjedd en rivende utvikling innenfor nettbrett og håndskriftsgjenkjenning. Nyere nettbrett har svært lav forsinkelse i input, høyoppløste skjermer og avanserte algoritmer for håndflategjenkjenning og håndskriftsgjenkjenning, som kombinert kan gjøre opplevelsen nærmere penn og papir. I dette arbeidet har vi undersøkt i hvor stor grad dagens teknologi er anvendelig i fag med bruk av matematisk notasjon og figurer. Vi valgte ut to fag på masternivå for maskiningeniører og lot en gruppe studenter gjøre øvingsoppgaver med henholdsvis penn og papir, et tekstredigeringsverktøy (Microsoft Word) og et nettbrett (iPad med Apple Pencil). Deretter analyserte vi opplevelsen til studentene gjennom dybdeintervju og evaluering av innsendte øvingsoppgaver. Resultatene viste at studentene opplevde nettbrett som et godt alternativ til penn og papir, og en klar forbedring sammenlignet med tekstredigeringsverktøy, men at gjenkjenningen av matematiske uttrykk fortsatt ikke er god nok til å brukes uten betydelig opplæring og trening.

\section{INTRODUKSJON}

Økt bruk av digitale innleveringer er et uttalt mål for Teknisk-Naturvitenskapelig (TN) fakultet ved Universitetet i Stavanger (UiS), og også for flere andre læresteder. Digitale innleveringer har en rekke fordeler:

- $\quad$ Mindre administrativt arbeid

- $\quad$ Feilkilder under sensur i forhold til dårlig lesbarhet eller utydelige kopier elimineres

- Høyere effektivitet for sensor, ikke avhengig av postgang

- Større fleksibilitet i forhold til sensur, besvarelsene er tilgjengelige overalt

- Digitale verktøy gir nye muligheter i forhold til tegning av diagrammer og nødvendige illustrasjoner.

- $\quad$ Digital vurdering gir mulighet for en dynamisk eksamen der alternativer og oppgaver endrer seg basert på hva man tidligere har valgt eller svart (se f.eks. Multi Smart Øving[1] som brukes i grunnskolen) 
- Digitale verktøy åpner for en annen type vurdering der man får hjelp av datamaskinen til å løse det regnetekniske slik at man kan teste andre typer egenskaper i forhold til matematisk modellering og tolkning av resultater

Et stort hinder for bruk av digital eksamen for ingeniørfag og tilsvarende studier er at fagene i stor grad krever bruk av matematisk notasjon og matematiske utregninger. Dagens mest brukte løsning for digital eksamen, Inspera, har i hovedsak to måter å levere matematiske uttrykk på. Den første er gjennom bruk av dokumentformatet LaTeX [2]. Dette er et typesettingssystem for å skrive matematiske uttrykk som er mye brukt til å skrive matematiske dokumenter. Den andre metoden er gjennom en grafisk symbolmeny der man klikker på symboler for å bygge opp matematiske uttrykk. Et eksempel på dette er gitt i Figur 1 som sammenligner et uttrykk skrevet med håndskrift fra en innlevert eksamen med Inspera sine innleveringsmetoder. LaTeX gir et pent resultat, men krever opplæring og kan være tungvint å jobbe effektivt med. Det er mer egnet til å føre inn allerede utregnede uttrykk og ikke til å gjøre selve utregningen. Symbolmenyen er enklere å bruke, men støtter ikke alle typer matematiske uttrykk.

Det matematisk-naturvitenskapelige fakultet ved Universitetet i Bergen utarbeidet nylig en rapport for digital undervisning og vurdering [3]. De påpekte i sine konklusjoner og anbefalinger at det var et gap mellom eksisterende funksjonalitet på digital eksamen på den ene siden og ønsker og behov knyttet til digital eksamen fra instituttenes side på den andre siden. En midlertidig løsning som benyttes er å scanne inn analoge besvarelser i etterkant av eksamen. Dette bevarer noen av fordelene som er listet over, men ikke alle. Dette har også blitt kritisert av studentene for å være tungvint. En av nøkkelsakene til studentene ved TN-fakultet i valget til Studentparlamentet i 2019 ved UiS var å «Bare ha digital eksamen der oppgaven kan føres inn på PC».

Et alternativ til å skrive inn de matematiske uttrykkene er å ha en flervalgsoppgave der man ikke viser selve utregningen, men kun velger riktig uttrykk som svar. Dette vil derimot føre til en begrensning i hva man får testet av studentenes ferdigheter. Et viktig element for ingeniørfag er å vurdere de kognitive ferdighetene. Det å ta et fysisk problem og sette dette over i et matematisk språk er en essensiell del av flere fag. Dette er også en kognitivt krevende oppgave som stiller krav til at studentene tar i bruk kunnskap og erfaring fra flere fag og evner å komme opp med og begrunne strategier for løsningsmetoden. Det er viktig at vurderingsformen også tester disse ferdighetene.

Forskning innenfor pedagogikk viser også at det er viktig med tilbakemeldinger til studentene for å opprettholde motivasjon og forbedre læringsprosessen, såkalt formativ vurdering[4,5]. Dersom innleveringsprosessen gjøres enklere kan det også bidra til at forelesere vil ha en høyere frekvens på innleveringer og tilbakemeldinger. Et annet aspekt ved dette prosjektet er at digitale verktøy åpner for en annen måte å undervise og vurdere på. I stedet for å løse en differensialligning manuelt kan studenten etter å ha definert problemet løse det digitalt. Man flytter dermed kompleksitet fra innøvde rutineferdigheter over på forståelse av den matematiske modelleringen og tolkning av resultatene. Det er i dag $\varnothing \mathrm{kt}$ bruk av digitale hjelpemidler i grunnskolen, f.eks. ved bruk av GeoGebra[6], og det er naturlig å tro at kommende studenter vil være vant med å bruke denne type verktøy i fremtiden. Det finnes også i dag dataassisterte vurderingsplattformer for matematikk som for eksempel STACK, der studenten får $\varnothing$ yeblikkelig tilbakemelding på om svaret er riktig[7]. Håndskriftgjenkjenning kan være en effektiv måte å skrive inn matematikken i slike verktøy, slik at man gjør det enklere å bruke sammenlignet med å bruke en spesialisert syntaks eller tungvinte grafiske brukergrensesnitt.

De siste årene har det kommet ny teknologi som gjør det interessant å se på mulighetene for digital levering av matematiske oppgaver. Skjermkvaliteten er bedre, og forsinkelser er tilnærmet borte grunnet raskere prosessorer. De nyeste nettbrettene har i dag også håndflategjenkjenning, som gjør at bruken av en digital penn blir nærmere bruk av papir. Det finnes nå også programvare som kan gjenkjenne håndskrift med matematiske uttrykk og konvertere disse til digital form. Et av disse er Microsoft sitt OneNote program, og et eksempel fra OneNote er vist i Figur 2. Vi ser at her har programmet tolket både plusstegnet og firetallet under kvadratroten feil, så denne funksjonaliteten må testes nærmere i konkrete fag for å vurdere egnetheten. 

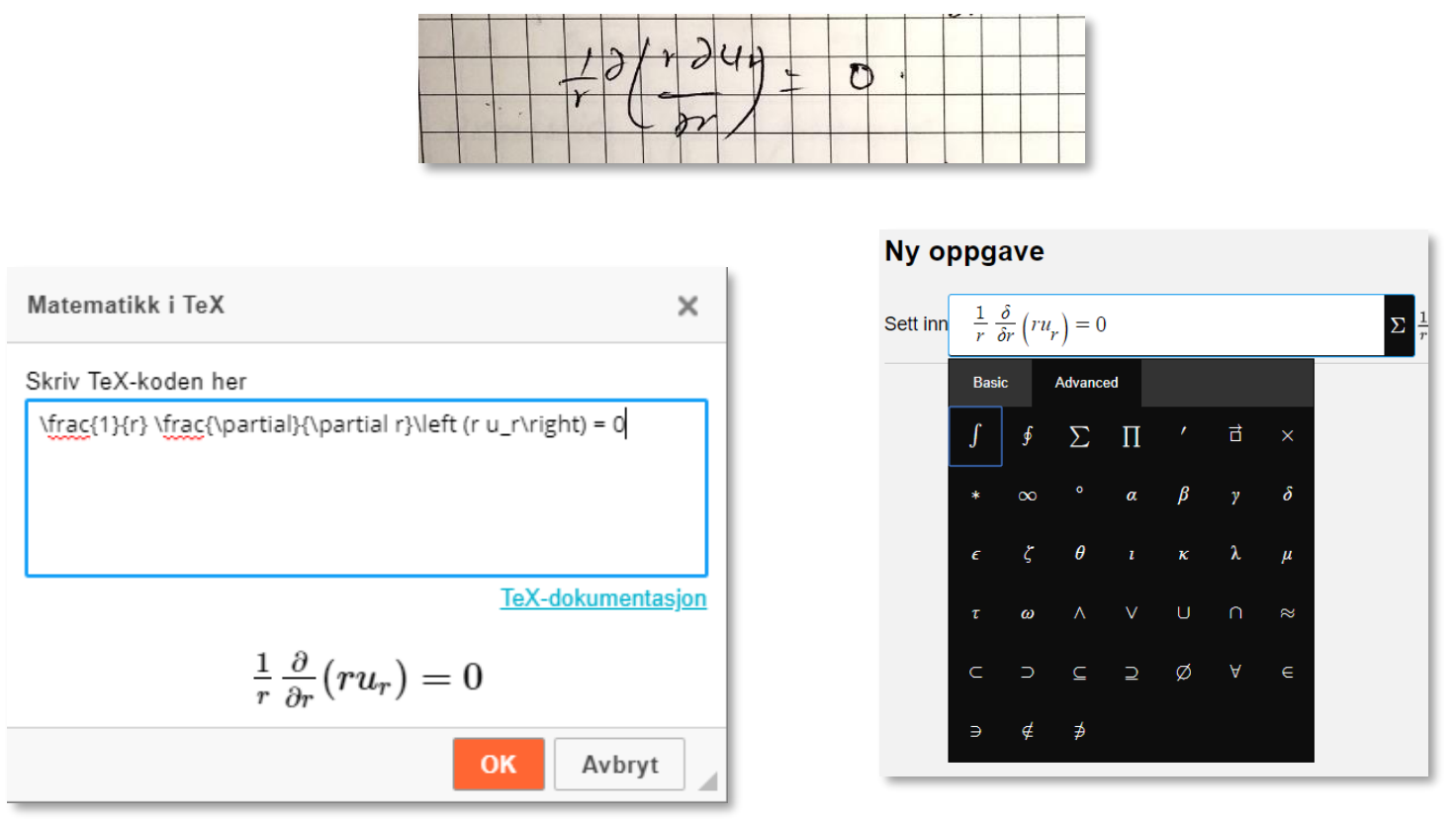

Fig. 1. Innskriving av matematisk uttrykk på ark (topp), med LaTeX-kode i Inspera (nede til venstre) og med grafisk symbolmeny i Inspera (nede til høyre).

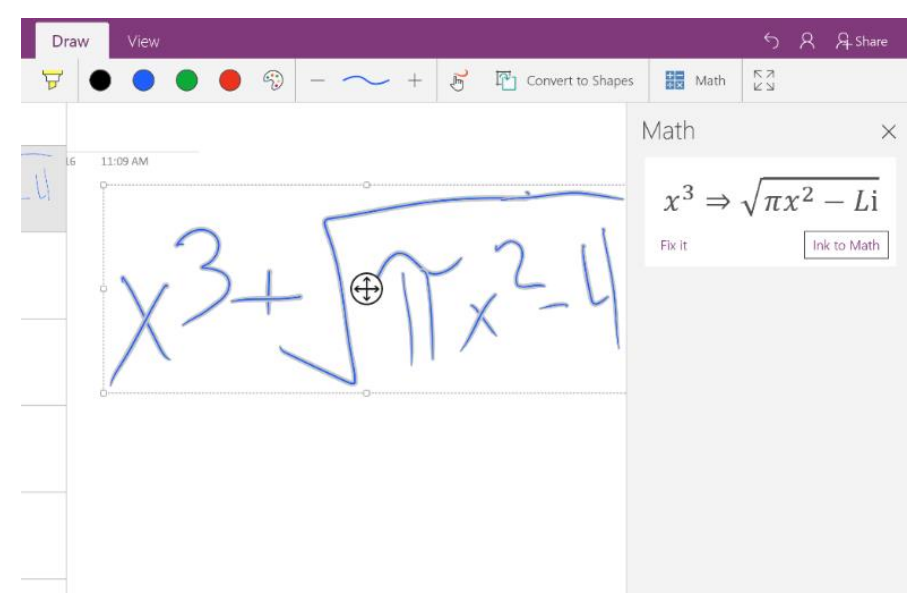

Fig. 2. Eksempel på konvertering fra håndskrift til digital fremstilling i Microsoft OneNote.

\section{METODE}

Etter en innledende studie av tilgjengelige nettbrett og programvare valgte vi nettbrettet Apple iPad Pro 4. generasjon med Apple Pencil 2 og programvaren MyScript Nebo til bruk i denne studien. Vi valgte deretter to fag med utstrakt bruk av matematisk notasjon, henholdsvis «MSK540 - Elementmetoder, videregående» og «MSK560 - Fluiddynamikk». Dette er begge fag som undervises i første semester av masterstudiet Konstruksjoner og materialer ved UiS. Vi rekrutterte fire studenter i hvert fag som på en frivillig basis deltok i studien. Studentene fikk først én times opplæring i programvaren. Prosjektet gikk videre ut på at deltakerne gjennomførte fire av fagenes ordinære innleveringer i henhold til følgende 
syklus: to av innleveringene skulle leveres med nettbrett, én med Microsoft Word og én med vanlig penn og papir. For å kunne sammenligne innleveringer ble dette gjort ved en rotasjonsordning, som illustrert i Tab. 1, slik at for hver innlevering ble to gjort med nettbrett, én med Microsoft Word og én med penn og papir.

Etter at innleveringene var levert fikk studentene en spørreundersøkelse der de skulle sammenligne bruken av de forskjellige verktøyene, og det ble også gjennomført et dybdeintervju av alle studentene. Én av studentene trakk seg under studien slik at totalt syv studenter fullførte prosjektet.

Tabell 1. Rotasjonsordning for innleveringer med forskjellige verkt $\phi y$

\begin{tabular}{|c|c|c|c|c|}
\hline \multirow{2}{*}{ Innlevering } & \multicolumn{4}{|c|}{ Student } \\
\cline { 2 - 5 } & A & B & C & D \\
\hline 1 & Nettbrett & Nettbrett & Word & Papir \\
\hline 2 & Papir & Nettbrett & Nettbrett & Word \\
\hline 3 & Word & Papir & Nettbrett & Nettbrett \\
\hline 4 & Nettbrett & Word & Papir & Nettbrett \\
\hline
\end{tabular}

\section{RESULTATER}

Tab. 2 viser nøkkelresultatene fra spørreundersøkelsen. Studentene syntes jevnt over det var lett å lære å bruke nettbrett, tre av studentene oppga middels lett og fire svært lett. Alle rapporterte at håndskriftsgjenkjenningen fungerte svært bra. Men til matematikk var det fire av studentene som meldte at det i liten grad fungerte til matematikk. En sammenligning av innleveringer med de forskjellige verktøyene er gitt i Fig. 3. Vi ser at uttrykkene med nettbrett og Word ser ganske like ut. Studentene rapporterte at bruk av nettbrett var betydelig raskere enn å bruke Word, så dette gir en klar fordel til bruk av nettbrett. Men sammenlignet med papir synes alle studentene at nettbrett var tregere å bruke enn papir. I dybdeintervjuene kom det frem at det var flere problemer med håndskriftgjenkjenningen som gjorde det vanskelig å bruke. Særlig gjaldt dette matriser, enkelte greske bokstaver, indekser og eksponenter. Det var også vanskelig å redigere et uttrykk etter at man hadde konvertert det til digital form. En klar fordel med penn og papir kan også sees i Fig. 3, ved at man kan tegne på topp av ligningene for å stryke ut ledd, skrive kommentarer og lignende. Dette var funksjonalitet som ikke fantes eller var god nok i programvaren, noe som gjorde det vanskelig for studentene å vise tankegangen i utregningene.

For videre arbeid bør det samarbeides med programvareutviklere for å få ønsket funksjonalitet for digitale innleveringer. Det bør også jobbes for å innarbeide funksjonalitet for håndskriftgjenkjenning i digitale eksamenssystemer som Inspera, samt beregningsassisterte vurderingsplattformer som STACK. Et ankepunkt er kostnaden ved nettbrett, utstyret som ble brukt i denne studien kostet NOK 16 000,- per stk. Men i løpet av kort tid siden studien ble gjort kan man få tilsvarende utstyr for kun NOK 4000,-Det er også mer vanlig at denne funksjonaliteten er tilgjengelig på bærbare PC-er, og det er grunn til å tro at flere studenter fremover vil ha mulighet til å benytte seg av håndskriftsgjenkjenning til notatskriving og digitale innleveringer. 
Tabell 2. Nфkkelresultater fra spфrreundersфkelsen.

\begin{tabular}{|c|c|c|c|}
\hline & Liten grad & Middels grad & Stor grad \\
\hline Det var lett å lære bruk av nettbrett & & 3 & 4 \\
\hline Nettbrett fungerer bra til skriving av tekst & & & 7 \\
\hline Nettbrett fungerer bra til skriving av matematikk & 4 & 3 & \\
\hline Nettbrett gir mindre tidsbruk sammenlignet med papir & 7 & & \\
\hline Nettbrett gir mindre tidsbruk sammenlignet med Word & & & 7 \\
\hline
\end{tabular}

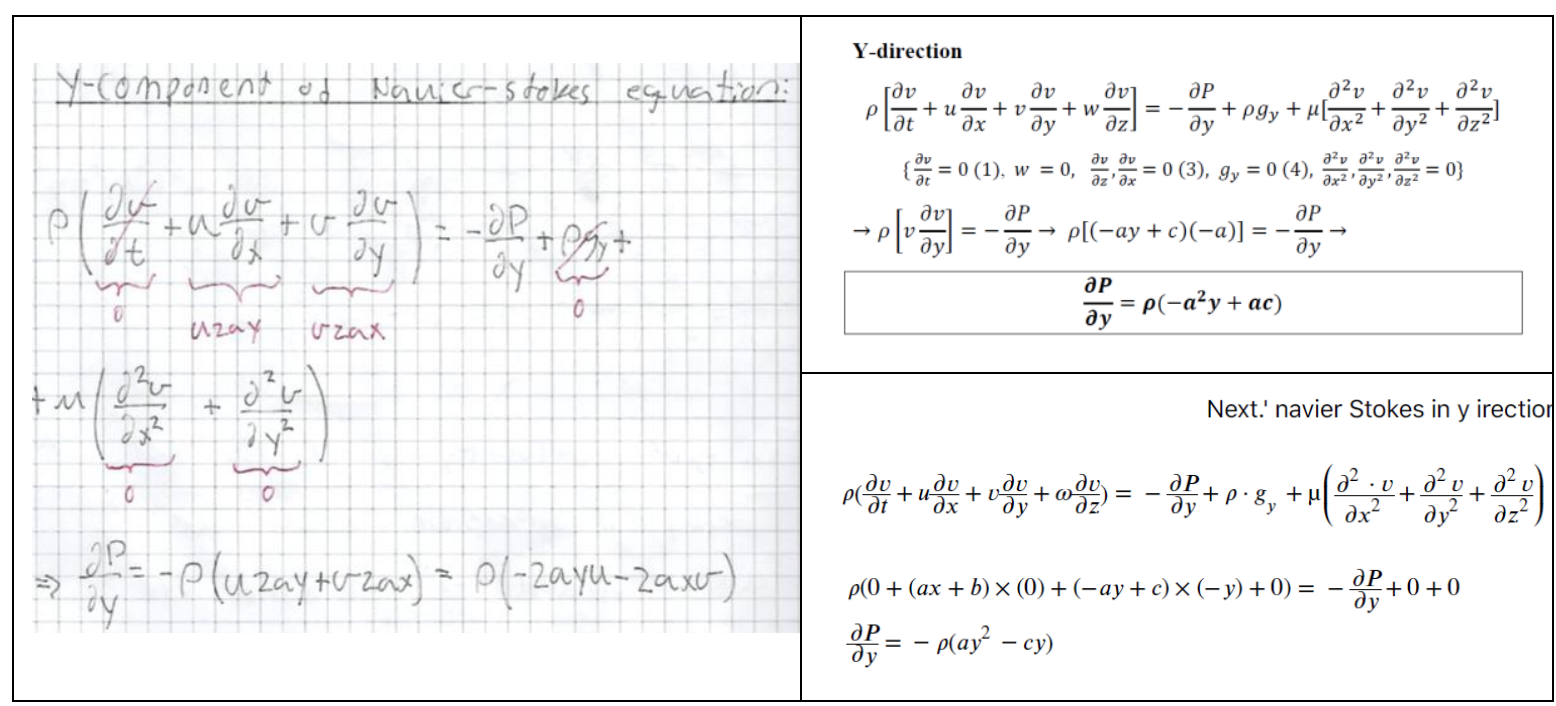

Fig. 3. Eksempel fra innlevering med penn og papir (venstre), Microsoft Word (høyre topp) og nettbrett med håndskriftsgjenkjenning (høyre bunn).

\section{REFERANSER}

[1] Selberg, S, Andresen, MS, Jørgensen, C, Ytrehus, Ø, Olsen, KR, Nerheim, MS, Gjerdevik, B (2016). Rapport fra arbeidsgruppen for digital undervisning og vurdering ved Det matematisk-naturvitenskapelige fakultet, Universitetet i Bergen.

[2] Gyldendal (2020). Multi Smart Øving - Adaptiv Læring i Matematikk. www.gyldendal.no/grunnskole/matematikk/multi-smart-oving/.

[3] Lamport, L (1994). LaTeX: a document preparation system: user's guide and reference manual. AddisonWesley.

[4] Hansen, MN, McAlpine, J (2018). Formativ vurdering-et didaktisk samspil: En undersøgelse af formativ vurdering i en dansk skolekontekst.

[5] Wilson, D (2014). Formativ vurdering gjør forskjell! En empirisk studie av lærernes forståelse av formativ vurdering som vitenskapelig fenomen og politisk konsept. NTNU.

[6] International GeoGebra Institute (2020) Free Math Apps - Used by over 100 Million Students \& Teachers Worldwide. www.geogebra.org/.

[7] Sangwin, C. (2015). Computer aided assessment of mathematics using STACK. In Selected regular lectures from the 12th international congress on mathematical education (pp. 695-713). Springer, Cham. 